\title{
Cartilage Restoration of Patellofemoral Lesions: A Systematic Review
}

CARTILAGE

I-17

(c) The Author(s) 2019

Article reuse guidelines:

sagepub.com/journals-permissions DOI: $10.1177 / 1947603519893076$

journals.sagepub.com/home/CAR

@SAGE

\author{
Renato Andrade 1,2,3, Joni Nunes ${ }^{4}$, Betina B. Hinckel5, Jordan Gruskay6, \\ Sebastiano Vasta7, Ricardo Bastos 1,2,8,9,10, J. Miguel Oliveira ${ }^{8,9,11}$, \\ Rui L. Reis $8,9,1$ I, Andreas H. Gomoll6, and João Espregueira-Mendes 1,2,9,12 (D)
}

\begin{abstract}
Purpose. This study aimed to systematically analyze the postoperative clinical, functional, and imaging outcomes, complications, reoperations, and failures following patellofemoral cartilage restoration surgery. Methods. This review was conducted according to the guidelines of Preferred Reporting Items for Systematic Reviews and Meta-Analyses (PRISMA). PubMed, EMBASE, and Cochrane Library databases were searched up to August 31 , 2018, to identify clinical studies that assessed surgical outcomes of patellofemoral cartilage restoration surgery. The Methodological Index for Non-Randomized Studies (MINORS) was used to assess study quality. Results. Forty-two studies were included comprising I,3।I knees (mean age of 33.7 years and 56\% males) and I,309 patellofemoral defects (89I patella, 254 trochlear, 95 bipolar, and 69 multiple defects, including the patella or trochlea) at a mean follow-up of 59.2 months. Restoration techniques included autologous chondrocyte implantation (56\%), particulated juvenile allograft cartilage (I2\%), autologous matrix-induced chondrogenesis (9\%), osteochondral autologous transplantation (9\%), and osteochondral allograft transplantation (7\%). Significant improvement in at least one score was present in almost all studies and these surpassed the minimal clinically important difference threshold. There was a weighted 19\%, 35\%, and 6\% rate of reported complications, reoperations, and failures, respectively. Concomitant patellofemoral surgery ( $51 \%$ of patients) mostly did not lead to statistically different postoperative outcomes. Conclusion. Numerous patellofemoral restoration techniques result in significant functional improvement with a low rate of failure. No definitive conclusions could be made to determine the best surgical technique since comparative studies on this topic are rare, and treatment choice should be made according to specific patient and defect characteristics. Level of evidence. Level IV, systematic review of level II to IV studies.
\end{abstract}

\section{Keywords}

patellofemoral, cartilage, chondral, osteochondral, restoration

\section{Introduction}

Focal chondral lesions of the knee are common and significantly decrease the quality of life and level of activity of patients. ${ }^{1,2}$ During routine knee arthroscopy, patellofemoral chondral lesions are often noted and account for up to $44 \%$ ( $11 \%$ to $36 \%$ in the patella, and $8 \%$ to $9 \%$ on the trochlea) of cartilage defects. ${ }^{3-5}$ Similarly, in professional athletes $18 \%$ to $37 \%$ of all knee cartilage lesions are located in the patellofemoral joint.6,7 However, not all patellofemoral lesions are symptomatic. As such, not every defect requires treatment, but patients with both structural patellofemoral defects and patellofemoral pain are candidates for cartilage restoration surgery. 1,2
Patellofemoral cartilage disease can result from patellar instability, maltracking, malalignment, acute or repetitive trauma, osteochondritis dissecans, or idiopathic degenerative changes. As such, the presence of a defect is often a sign of associated, underlying pathology that may require additional operative intervention. $1,8,9$ The presence of malalignment and instability are variable (40\% to $60 \%)$, and concurrent procedures such as tibial tubercle osteotomy (TTO) and/or lateral retinacular release are performed in up to $75 \%$ and $60 \%$ of cases, respectively. ${ }^{10-21}$ Unfortunately, quality of reporting of associated pathology and concomitant procedures lack consistency and may not represent their true incidence. ${ }^{22}$ 
The first-line treatment is nonoperative management. 23,24 When this approach fails, the surgical management should be considered with the goals of restoring cartilage surface congruity, reestablishing normal patellofemoral biomechanics, alleviating symptoms, and improving function and quality of life. The choice of technique is influenced by the individual (e.g., age, activity level, body mass index and patellofemoral alignment) and morphological defect characteristics (e.g., location, size, depth, and containment). ${ }^{23}$

In the past decade, a variety of surgical options have emerged for treating symptomatic patellofemoral cartilage lesions, but a gold standard treatment has not been established yet. 1,8,9,23,25-27 Even though there are many case series reporting improved clinical outcomes after a variety of cartilage repair procedures (including microfracture [MFx], autologous chondrocyte implantation [ACI], osteochondral allograft transplantation [OCA], and osteochondral autograft transfer [OAT]); there is a lack of randomized controlled trials or comparative studies in the patellofemoral joint (only one study comparing techniques ${ }^{28}$ ).

Hence, the purpose of this study is to systematically analyze the postoperative clinical, functional and imaging outcomes, complications, reoperations, and failures following patellofemoral cartilage restoration surgery and assess which surgical technique yields superior outcomes. It was hypothesized that no specific surgical technique is clearly superior, and that each technique is suited to and utilized to treat specific situations.

\section{Methods}

The systematic review was conducted according the Preferred Reporting Items for Systematic Reviews and Meta-Analyses (PRISMA) statement. ${ }^{29}$ The protocol for this systematic review was prospectively registered at the International Prospective Register of Systematic Reviews
(PROSPERO; http://www.crd.york.ac.uk/prospero/; ID: CRD42018085772).

\section{Search Strategy}

We searched PubMed, EMBASE, and Cochrane Library electronic databases from database inception to August 31, 2018 for clinical studies that assessed surgical outcomes of patellofemoral focal cartilage restoration surgery. Searches were conducted combining the following key terms: patella*, patellofemoral, femoropatellar, trochlea*, cartilag*, articul*, chondral, mosaicplasty, OAT, "osteochondral autograft transfer," ACI, MACI, "autologous chondrocyte implantation," "matrix-induced autologous chondrocytes implantation," "cartilage transplantation," microfracture, drilling, allograft, chondroplasty; with resource to the Boolean operators (AND) and (OR) and the command [Ti/ $\mathrm{Ab}$. Search strategy for each database can be seen in Supplemental Material 1 (available online).

\section{Study Selection}

All records were exported to EndNote X7 (Thomson and Reuters) and duplicates were removed by software filter and then checked manually. All titles and abstracts were independently screened for inclusion by 2 authors (R.A. and J.N.); any disagreement was resolved by discussion until consensus was reached. The reference lists from published patellofemoral cartilage surgery studies were also checked for additional potentially relevant studies for inclusion. The full-text versions of all potentially relevant studies were obtained and screened for eligibility by the same two authors. The inclusion criteria were (1) studies investigating patellofemoral articular cartilage defects treated surgically; (2) assessment of postoperative clinical, functional, or imaging outcome; (3) clinical, functional, or imaging

'Clínica do Dragão, Espregueira-Mendes Sports Centre - FIFA Medical Centre of Excellence, Porto, Portugal

2Dom Henrique Research Centre, Porto, Portugal

${ }^{3}$ Faculty of Sports, University of Porto, Porto, Portugal

${ }^{4}$ Hospital de Braga, Braga, Portugal

5Brigham and Woman's Hospital, Harvard Medical School, Boston, MA, USA

6Hospital for Special Surgery, New York, NY, USA

${ }^{7}$ Orthopaedics and Trauma Surgery Department, University Campus Bio-Medico of Rome, Rome, Italy

83B's Research Group, I3Bs-Research Institute on Biomaterials, Biodegradables and Biomimetics, University of Minho, Headquarters of the European Institute of Excellence on Tissue Engineering and Regenerative Medicine, Barco, Guimarães, Portugal

ICVS/3B's-PT Government Associate Laboratory, Braga/Guimarães, Portugal

I0Fluminense Federal University, Niterói, Rio de Janeiro, Brazil

IIThe Discoveries Centre for Regenerative and Precision Medicine, Headquarters at University of Minho, Barco, Guimarães, Portugal

12 Orthopaedics Department of Minho University, Braga, Portugal

Supplementary material for this article is available on the Cartilage website at https://journals.sagepub.com/home/CAR.

Corresponding Author:

João Espregueira-Mendes, Clínica do Dragão, Espregueira-Mendes Sports Centre, FIFA Medical Centre of Excellence, Via Futebol Clube do Porto, F. C. Porto Stadium, Porto, Portugal.

Email: espregueira@dhresearchcentre.com 
outcome data specifically assessing the patellofemoral joint; and (4) English language studies. Abstracts that provided enough data according to the inclusion criteria defined above were considered for inclusion. Reviews, meta-analyses, technical notes or expert opinions, single case studies, animal, or basic science studies were excluded. Additional exclusion criteria included studies focusing on (1) skeletally immature patients; (2) articular cartilage surgery as a secondary, concomitant procedure to primary knee surgery (e.g., medial patellofemoral ligament reconstruction, when the outcomes of patients with cartilage restoration was not reported separately); (3) patellofemoral arthroplasty, as well as studies, including (4) osteoarthritis instead of focal articular cartilage lesions' (5) defects exclusively located at the tibiofemoral joint or without a separate subgroup for the patellofemoral results; and (6) studies in which the postoperative clinical, functional, or imaging outcome could not be objectively extracted.

\section{Data Extraction}

All data were extracted to Microsoft Excel files with predetermined outcomes of interest. The population demographics (sample size, age, body mass index, gender) and defect characteristics (location, size, and grade) were extracted. Information regarding patellofemoral instability risk factors and associated patellofemoral surgical procedures was noted. Data were subgrouped according to surgical technique: OAT, including mosaicplasty; OCA; particulated juvenile allograft cartilage transplantation (PJAC); MFx; autologous matrix-induced chondrogenesis (AMIC); ACI), including periosteum covered ACI ( $\mathrm{pACI}$ ), collagen covered $\mathrm{ACI}(\mathrm{cACI})$, and matrix-induced $\mathrm{ACI}(\mathrm{mACI})$; bone marrow aspirate concentrate (BMAC); and synthetic graft implantation. Postoperative outcomes were also extracted, including length of follow-up, complications, failures, imaging, and patient-reported functional scores. Complications were grouped as minor and major. Minor complications did not require further surgical intervention while major complications directly resulted in return to the operating room, with the exception of removal of hardware following tibial tuberosity transfer. The definition of "failure" varied in each study. As such, the description and rate of failure was individually collected for each study. Then, to facilitate pooling of outcomes with the purpose of evaluating collective failure rates, "failure" was defined in the present investigation as a case that required an additional surgical intervention to revise the index cartilage restoration procedure, either with another cartilage restoration procedure or with patellofemoral arthroplasty or total knee arthroplasty.

Concerning functional outcomes, when available, the mean and standard deviation (SD) from preoperative and last follow-up endpoints were recorded. If the mean values were not reported but the individual patient scoring was available, mean and SD were computed. The $P$ value from preoperative to last follow-up was recorded and mean improvement calculated from reported averages. To determine the significance of improvement of functional scores, the mean change was compared with the minimal clinically important difference (MCID) reported in the scientific literature for the most representative scores, including the International Knee Documentation Committee (IKDC) score (change of 3.19 to 16.7 points), ${ }^{30}$ Lysholm score (change of 10.1 points), ${ }^{30}$ and Knee injury and Osteoarthritis Outcome Score (KOOS) score (change of 8 to 10 points). ${ }^{31}$ While the MCID for the Kujala score has not been determined so far, it has been suggested that a change exceeding 10 points is regarded as clinically meaningful. ${ }^{32,33}$

\section{Methodological Quality}

The methodological quality was assessed with the Methodological Index for Non-Randomized Studies (MINORS). ${ }^{34}$ This scale is a validated instrument consisting of 12 items designed to assess the methodological quality of nonrandomized surgical studies. The last 4 items are specific to comparative studies. Each item was scored as 0 if not reported, 1 when reported but inadequate, and 2 when reported and adequate. Maximum score is 16 for non-comparative studies and 24 for comparative studies. The level of evidence was also recorded. Two authors (R.A. and J.N.) independently assessed the methodological quality of all included articles and all disagreements were discussed until consensus was reached.

\section{Statistical Analysis}

Data are presented with descriptive statistics (weighted mean, SD, and ranges). Functional outcome improvement was determined by computing the difference of presurgery to last follow-up averages. Results were pooled for each of the predetermined surgical subgroups using weighted means for presurgery and last follow-up and means and ranges for the improvement. This pooled analysis was performed when the functional score was reported for both preand postoperative endpoints. Because of the lack of comparative studies and high heterogeneity in the surgical techniques, use of concomitant patellofemoral surgical procedures and reported functional outcomes, a meta-analysis was not performed.

\section{Results}

\section{Study Selection and Characteristics}

The database and manual searches yielded a total of 968 titles and abstracts. After removing duplicate articles, 610 abstracts were screened and 84 full-text articles were 
reviewed for inclusion. Forty-two studies ${ }^{10-18,20,21,28,35-64}$ met the eligibility criteria and were included in this review (Fig. 1). The majority of included studies were case series (32 studies, 76\%). There were only 6 prospective cohort studies (14\%), 2 of which compared techniques-one comparing pACI with or without TTO, and other comparing mACI and BMAC. There were no randomized controlled trials.

\section{Population and Surgical Characteristics}

A total of 1,314 knees were included comprising 891 patella defects, 266 trochlear defects, 95 patellofemoral bipolar, and 69 multiple defects, including the patella or trochlea (Table 1). There were more males $(56 \%)$ than females (44\%). Mean age was 33.7 years and mean body mass index was $26.0 \mathrm{~kg} / \mathrm{m}^{2}$. Mean age and body mass index did not vary substantially across techniques (OAT, 32 years and $24.9 \mathrm{~kg} / \mathrm{m}^{2}$; OCA 34.4 years and $26.7 \mathrm{~kg} / \mathrm{m}^{2}$; PJAC, 27.3 years and $27.3 \mathrm{~kg} / \mathrm{m}^{2}$; AMIC, 36.4 years and $25.2 \mathrm{~kg} / \mathrm{m}^{2}$; ACI, 34.7 years and $26.7 \mathrm{~kg} / \mathrm{m}^{2}$ ).

Cartilage defects were most commonly classified using Outerbridge or International Cartilage Repair Society (ICRS) grading (Outerbridge III/IV, $n=149$; modified Outerbridge III/IV, $n=37$; ICRS III/IV, $n=$ 639; ICRS II, $n=11$; not reported, $n=478$ ). Most defects were unipolar, independent of the technique used (OAT, $100 \%$; OCA, $84 \%$; PJCT, 97\%; AMIC, 100\%; ACI, $85 \%$ ). The mean cartilage defect sizes were larger with the OCA and ACI techniques $\left(8.1 \mathrm{~cm}^{2}\right.$ and $5.0 \mathrm{~cm}^{2}$, respectively) than OAT, PJCT and AMIC $\left(1.9 \mathrm{~cm}^{2}, 2.2 \mathrm{~cm}^{2}\right.$, and 3.6 $\mathrm{cm}^{2}$, respectively).

There were 22 groups of patients with anatomical patellofemoral risk factors ( 5 of those only comprised patients with established anatomical patellofemoral risk factors), 15 groups without anatomical patellofemoral risk factors and 8 studies where anatomical patellofemoral risk factors were not reported. One study ${ }^{35}$ was only composed of patients with patellofemoral instability and six studies included a subset of patients with diagnosis of patellofemoral instability. ${ }^{11,20,21,40,41,43}$ The ACI technique was the most frequent (24 studies, 56\%), followed by PJAC ( 5 studies, 12\%), AMIC and OAT (each 4 studies, 9\%) and OCA (3 studies, $7 \%$ ). Concomitant patellofemoral surgical procedures were performed in $51 \%$ of patients and mostly included TTO ( $n$ $=425)$, lateral retinacular release $(n=188)$, trochleoplasty $(n=64)$, and medial patellofemoral ligament reconstruction $(n=55)$.

\section{Postoperative Clinical and Functional Outcome Measures}

The weighted mean follow-up was 59.2 months (range, 8.2153.6 months). Preoperative, last follow-up, and improvement of clinical and functional outcome measures grouped by surgical technique are presented in Table 2 . A direct comparison between surgical techniques was not possible due to the lack of comparative studies. The IKDC score was the most commonly used patient-report outcome measure (25 studies, 58\%) and showed higher weighted improvement after OCA (31.7 points) and AMIC (32.5 points) compared with OAT (27.2 points), PJAC (28.4 points), and ACI (26.8 points). Meanwhile, for the Lysholm score, the OAT (26.1 points) and AMIC (27.0 points) techniques were superior to ACI (22.5 points). The opposite was seen for the Kujala score with ACI (29.0 points) showing superior improvement to OAT (20.3 points) and AMIC (26.0 points). For the KOOS total score, there was a superiority of AMIC (39.8 points) over PJAC (16.4 points) and ACI (16.4 points) techniques. However, when considering the KOOS subscores, the ACI technique was superior for KOOS sports and quality of life subscore comparing to AMIC, but comparable for the other KOOS subscores. The techniques that showed superior improvements regarding Kujala, IKDC, Lysholm and KOOS scores were the same that showed superior absolute scores at final follow-up. In the IKDC all techniques showed superior final follow-up absolute scores compared with ACI.

Improvement in at least 1 score was present in all but 6 studies ( 2 only had magnetic resonance imaging [MRI] results ${ }^{21,59}$ and 4 only reported follow-up scores $\left.28,41,49,50\right)$ and 32 studies reported a significant improvement in at least 1 score. Generally, all techniques achieved and surpassed the MCID threshold reported in the literature. All studies that showed improvement for the IKDC (12 of 12 studies, for OAT, ${ }^{20}$ OCA, ${ }^{39,40}$ PJAC, $, 2,43$ AMIC, 45,47 and ACI ${ }^{11,12,14,28,52-56,61)}$, and Kujala ( 6 of 6 studies, for OAT, ${ }^{36}$ AMIC, 44,46 and ACI $22,56,58$ ) scores achieved the MCID. The same occurred for most of studies for Lysholm (12 of 14 studies, for OAT, ${ }^{35-37}$ AMIC ${ }^{45}$ and $\mathrm{ACI} 10,14,28,53,54,56,58,60)$ and KOOS scores (4 of 5 studies, for PJAC, ${ }^{16,42} \mathrm{AMIC},{ }^{47}$ and $\left.\mathrm{ACI}{ }^{15}\right)$. For the $\mathrm{ACI}$ technique, there were 2 studies ${ }^{18,51}$ showing an improvement that did not achieve the MCID for the Lysholm and another ${ }^{56}$ for the KOOS score.

Patient satisfaction was infrequently reported among techniques (12 studies, 28\%) and comparable rates of satisfaction were seen between OCA (weighted mean 89\%) and ACI (weighted mean 84\%). However, synthetic scaffolding (Trufit) reported a low rate of patient satisfaction (10\%). The clinical and functional outcomes of each study, including their improvement, significance ( $P$ value) and patient satisfaction are presented in Supplemental Material 2.

\section{Imaging Outcomes}

A total of 28 studies reported on imaging outcomes (27 studies on MRI and 1 study on radiographs). The specific imaging outcomes for each of the 28 studies are presented in Supplemental Material 2. 


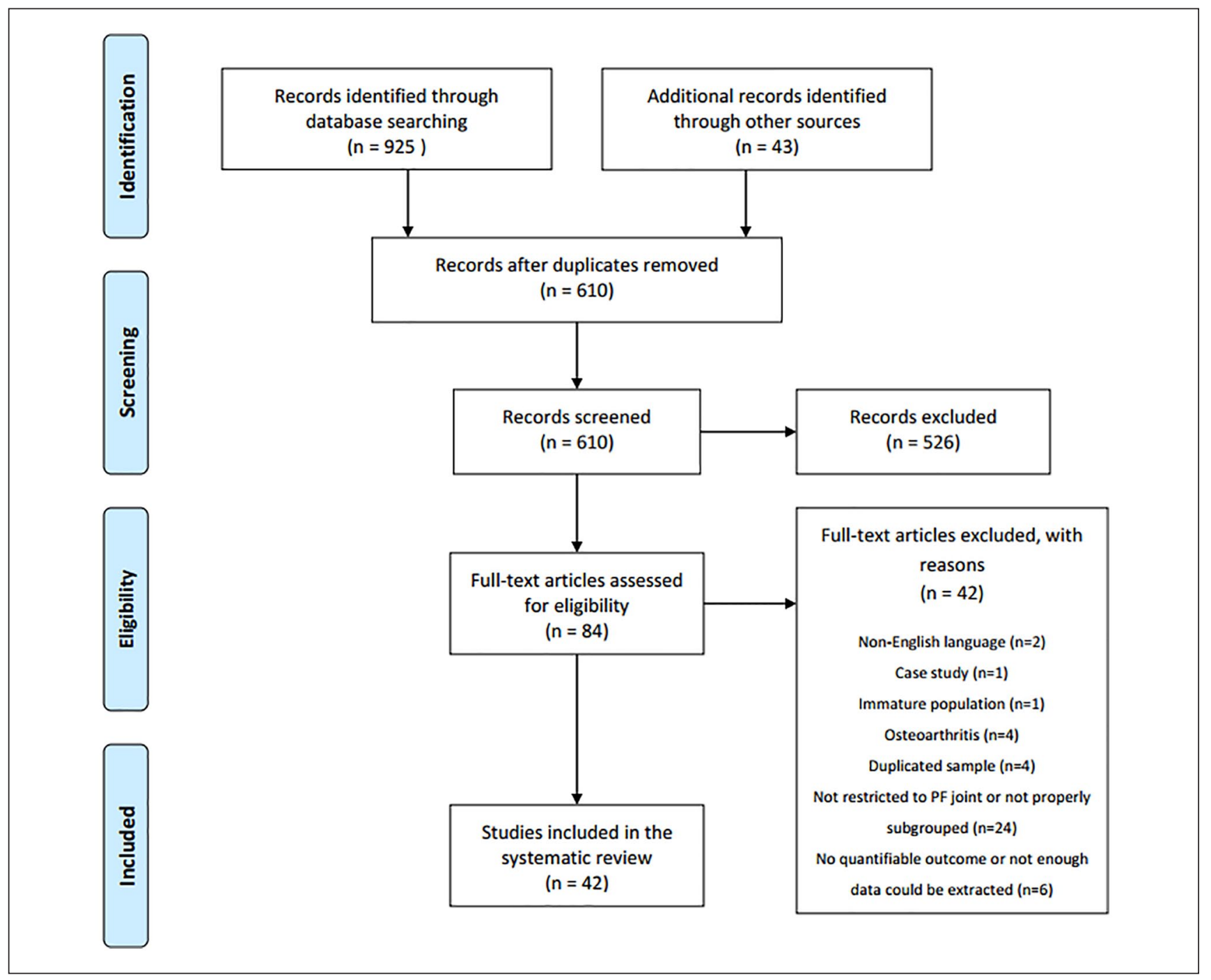

Figure I. Preferred Reporting Items for Systematic Reviews and Meta-Analyses (PRISMA) flowchart.

For OAT, MRI results we reported in 3 studies $(n=57)$. One study ${ }^{20}$ showed a good repair fill $(>67 \%)$ in all 14 patients assessed (from the initial 22 included), but a mismatch between the subchondral plate of the plug and the surrounding native patella. There were no cases with a smooth transition between host and donor cartilage, and fissures $>2 \mathrm{~mm}$ were found in $36 \%$ of patients. While $71 \%$ had complete trabecular incorporation with flush plug appearance, mild edema was found was found in $29 \%$ of patients and moderate edema in another $29 \%$. Another study ${ }^{35}$ showed that all autografts $(n=10)$ achieved a nearly normal cartilage appearance (ICRS 1A), with the periphery of the plug classified as grade $1 \mathrm{~A}(60 \%)$, grade $1 \mathrm{~B}(20 \%)$, grade $2(10 \%)$, and grade $3 \mathrm{~B}(10 \%)$. There were no fissures in the graft-receptor interface in $60 \%$ of patients but bone marrow edema $(<1 \mathrm{~cm})$ was noted around the osteochondral plug in $80 \%$ of patients. Astur et al. ${ }^{36}$ reported that all 33 patients achieved a complete osseous integration without surface incongruence at 12 months follow-up. These findings were supported by T2-mapping results showing color stratification of the repair cartilage that was close to approximating normal cartilage.

For OCA, on radiographic results were reported in only one study ( $n=12$ of the 20 patients included), demonstrating that $50 \%$ of patients had mild patellofemoral arthrosis and $33 \%$ no evidence of arthrosis. 38

PJAC MRI outcomes were reported in 4 studies ( $n=90$ of the 102 patients included) achieved a reasonable defect fill $(>33 \%)$ in more than half of the patients and very good $(>67 \%)$ in $56 \%$ to $90 \%$ of the patients, with graft hypertrophy rates ranging from $0 \%$ to $33 \%$ of patients. ${ }^{21,41-43}$ Subchondral marrow changes were frequently reported (range, $0 \%$ to $90 \%)^{21,41-43}$ as well as synovitis (range, $0 \%$ to 58 ), ${ }^{21,41,42}$ but low rates of graft displacement were noted (range, 3\% to 
$7 \%$ ). ${ }^{21,42}$ T2 mapping technique was performed in 3 studies ( $n$ $=75$ ) and revealed prolonged mean $\mathrm{T} 2$ relaxation time at the graft site at both the deep and superficial zone compared with adjacent normal cartilage, ${ }^{21,42,43}$ but this difference improved (decreased) overtime. ${ }^{21}$

The AMIC technique MRI outcomes were reported in 3 studies $(n=27)$. Consistent results were seen on magnetic resonance observation of cartilage repair tissue (MOCART) score at around 24 months (range, 53\% to 58\%). ${ }^{44,46,47}$ Incomplete filling was found in $40 \%$ to $60 \%$ of patients and graft hypertrophy in $20 \%$ to $40 \%$. MRIs revealed that $40 \%$ to $80 \%$ patients had complete integration to border zone, $70 \%$ to $100 \%$ had irregular surface, $60 \%$ to $100 \%$ had inhomogenous structure, and only $0 \%$ to $10 \%$ had isointense signal. None had an intact subchondral lamina and $0 \%$ to $60 \%$ patients had intact subchondral bone. No adhesions were reported but effusions were noted in up to $30 \%$ of patients. ${ }^{44,46}$

A total of 14 studies ( $n=364$ out of 466 patients included) reported the MRI outcomes of the ACI technique. The MOCART score was reported in 5 studies, but using different scoring methods: total score 73 to 79 points; 59,60 composite score 3.2 to 3.4 points; ${ }^{17,62}$ and modified score 13.7 points. ${ }^{56} \mathrm{MRI}$ findings demonstrated high rates of moderate to high defect filling $(>50 \%)$ in $55 \%$ to $100 \%$ of patients and graft hypertrophy in $0 \%$ to $33 \%$ of patients $(n=135$ out of 191). ${ }^{15,17,56,57,61,62}$ Complete integration to the border zone was found in $47 \%$ up to $88 \%$ of patients ( $n=135$ out of 191$),{ }^{15,17,57,61,62}$ with $84 \%$ to $91 \%$ with smooth surface or focal changes $(n=48 \text { out of } 91)^{17,62}$ and $58 \%$ with intact surface without irregularities $(n=24$ out of 31$) .{ }^{57}$ The structure of the repair tissue was homogeneous in $21 \%$ to $58 \%$ of patients in 2 studies ( $n=58$ out of 68$)^{15,57}$ and $85 \%$ to $95 \%$ had more than $50 \%$ of homogenous repaired structure in 2 other studies ( $n=48$ out of 91$).{ }^{17,62}$ The signal was mostly hypointense or isotense in most patients $(88 \%$ to $95 \%, n=$ 66 out of 121). ${ }^{17,57,62}$ The subchondral lamina was almost always intact ( $94 \%$ to $100 \%, n=66$ out of 121$),{ }^{17,57,62}$ as well as the subchondral bone ( $58 \%$ to $96 \%, n=82$ out of 140). ${ }^{17,57,61,62}$ Joint effusion varied considerably ( $0 \%$ to $88 \%$, $n=66$ out of 121) 17,57,62 and adhesions were only reported in 1 study in $8 \%$ of patients ( $n=24$ out of 30$) .57$ T2-mapping results $(n=22)$ revealed increased but comparable T2 values of repaired cartilage tissue and native cartilage, increasing from the deep to the superficial layers regardless of knee position. 59,60

\section{Complications, Reoperations, and Failures}

Complications were inconsistently reported and only mentioned in 11 studies (26\%). 15,16,36,37,45,47,52,54,58,62 Overall, there was a weighted $19 \%$ rate of reported complications (57 complications in 302 patients) and only 5\% of those were considered major (Supplemental Material 3). The was a similar rate of complications for OAT $(12 \%$, range $9 \%$ to $15 \%)$, ACI $(17.4 \%$, range $0 \%$ to $76 \%$ ), and $\mathrm{AMIC}$ ( $25 \%$, range $0 \%$ to $50 \%$ ) techniques, but higher for PJAC (38\%). OCA studies reported no complications other than failures.

The rate of reoperation was reported in 18 studies $^{10,12,14,15,17,39-41,43,44,46,48,53,54,57,58,61,63}$ accounting for a weighted rate of $35 \%$ (167 reoperations in 484 patients). The weighted rates of reoperation were generally high with $12 \%$ (range, $0 \%$ to $33 \%$ ) for PJAC, $20 \%$ for OAT, $37 \%(0 \%$ to $67 \%$ ) for ACI, and $41 \%$ (range $21 \%$ to $61 \%$ ) for OCA. The use of synthetic resorbable scaffolds resulted in a considerably higher rate of reoperations $(70 \%)$. On the other hand, the BMAC implantation had a low rate of reoperations $(6 \%)$. Reoperations due to removal of hardware were not considered.

Failures were reported in 18 studies. ${ }^{10-15,18,37-40,52,54,57,62-64}$ Failure was most commonly defined as delamination of the repaired graft and/or the need for surgical revision (Supplemental Material 4). Accounting only for failures that required cartilage revision surgery or conversion to knee arthroplasty, ${ }^{12,14,15,18,39,40,52,54,57,64}$ there was a failure rate of $6 \%$ (27 complications in 420 procedures). OCA had a higher failure rate $(16 \%, 9$ in 59) than ACI $(5 \%, 18$ in 330). The use of cell-free biphasic collagen-hydroxyapatite osteochondral scaffold did not lead to any failures $(0 \%$ in $n=34$ ).

Complication, reoperations, and failure rates for each included study are presented in Supplemental Material 2.

\section{Concomitant Procedures}

A total of 18 studies reported outcomes related to articular cartilage techniques associated with other patellofemoral surgical procedures. Thirteen studies $10,11,15,17,18,43,45,48,51,57,61,62,64$ reported that there were no significant differences in postoperative outcomes when a concomitant procedure was performed. Three studies showed that the addition of TTO to ACI led to significantly improved postoperative functional scores. ${ }^{12,14,58}$ Gillogly et al. ${ }^{54}$ reported that ACI and concomitant trochleoplasty and anteriomedialization TTO showed greater improvement in functional scores but without statistical significance. Conversely, Nho et al. ${ }^{20}$ reported that adding TTO to OAT showed a nonstatistically significant trend toward worse outcomes. Siebold et al. ${ }^{56}$ performed minimally invasive ACI (spheroids technique) combined with medial patellofemoral ligament reconstruction in a sample of patients with recurrent patellar dislocation and traumatic grade IV cartilage lesions. Their findings demonstrated good MRI results with filling of the defect in $80 \%$ of the patients and no episodes of patellar redislocation, but without significant postoperative improvements in functional outcomes. 


\section{Subgroup Analysis}

Only a few studies performed a subgroup analysis to determine the effect of location and other defect-related factors on post-operative outcomes. ${ }^{10,11,15,36,43,50-52,61}$ Trochlear defects were associated with better, longer lasting score improvements as compared with patellar defects in 2 studies, ${ }^{52,61}$ while several other investigations reported no significant differences between the 2 locations. ${ }^{10,43}$ Farr et al. ${ }^{10}$ reported better integration of repaired tissue into the border zone on the patella when compared with trochlear defects. In patella-only studies, there was a trend toward better outcomes for lesions at the lateral rather than lateral plus medial facets, ${ }^{36,50}$ but there were also reports of no differences between lateral, central, and medial lesions. ${ }^{11,15}$ One study ${ }^{51}$ reported worse outcomes for bipolar compared with multiple unipolar lesions.

\section{Methodological Quality}

The mean MINORS score was $9.9 \pm 1.8$ (out of 16) and $16.8 \pm 3.7$ (out of 24) for noncomparative and comparative scores, respectively (Table 1). Major methodological concerns were lack of a priori sample size calculation (95\%) and lack or inadequate blinding of the outcome assessment ( $76 \%$ and $24 \%$, respectively). Inadequate planning of follow-up assessment of main outcomes (55\%) and a nonprospective data collection $(38 \%)$ were also methodological concerns. Insufficient follow-up timing (i.e., at least 1 patient with less than 24 months of follow-up) was seen in 33\% of the studies. As most of the studies were noncomparative (74\%), concerns are raised regarding the lack of control group, leading to high risk of selection bias. In comparative studies, the lack of randomization $(100 \%$ - high risk of selection bias) and adequate surgical comparison (only 1 study compared 2 different surgical treatments) were also identified methodological concerns. Specific scoring of the included studies is available by request to the authors.

\section{Discussion}

The most important finding of this study was the significant improvement in functional post-operative outcomes following patella and/or trochlear cartilage restoration surgery, regardless of surgical technique employed-OAT, OCA, PJAC or ACI. Each option demonstrated a low failure rate, with a unique postoperative complication risk profile. Thus, the choice of the surgical technique should be based on and adjusted to the patient's needs and characteristics (level of activity, age, body mass index, and comorbidities) and to the defect characteristics (location, size, containment). For this purpose, treatment algorithms have been developed ${ }^{14}$ and advantages of surgical techniques have been discussed. ${ }^{1}$
A previous systematic review on cartilage restoration evaluating 28 studies found that ACI was the most commonly reported technique and that all of the evaluated techniques lead to symptomatic improvement with low complication rates. ${ }^{65}$ With the additional 14 studies included in this current review, for a total of 42 , we confirmed that significant clinical and functional improvement occurs postoperatively with most cartilage restoration techniques. However, our investigation also evaluates and reports on the considerable rate of failures and reoperations following cartilage restoration surgery that was not evaluated in the previous study. We believe that these findings provide valuable information for surgeons and patients, helping guide decision making and to set realistic expectations. Furthermore, we included imaging results highlighting the quality of the repaired cartilage.

Cartilage restorative techniques of the patellofemoral joint can be considered as reconstructive or reparative procedures. The reconstructive procedures comprise the OAT (autologous) and OCA (from a donor) techniques and involves transplanting osteochondral plugs containing mature hyaline cartilage. The reparative techniques entail cartilage regeneration of hyaline-like or fibrocartilage by bone marrow elements (MFx, AMIC, or BMAC) or chondrocytes (ACI or PJAC). MFx involves the perforation of the subchondral bone to release bone marrow elements; this can be augmented by combining with a I/III collagen or hyaluronan-based scaffold (AMIC). Instead, bone marrow elements can be collected and concentrated from a remote source (not in the defect area), BMAC, and implanted in a synthetic, porcine I/III collagen, or hyaluronan-based membrane. The bone marrow elements induce the extracellular matrix production by cells derived from pluripotent cells. The chondrocyte-based therapies use either autologous cultured chondrocytes (ACI) - which can be implanted using a periosteum patch $(\mathrm{pACI})$, a porcine I/III collagen patch (cACI), or a matrix-based membrane containing seeded chondrocytes (mACI) - or use particulated immature chondrocytes from young children donors (PJAC). Those chondrocytes will be responsible for the extracellular matrix production.

The postoperative functional scores improved significantly up to the last follow-up endpoint for all techniques. There was large variability in the amount of improvement for each technique depending on the specific outcome measure. The OAT and AMIC techniques consistently showed superior improvements relative to ACI for IKDC, KOOS, and Lysholm scores, which may be explained by the increased size of the defects included for the ACI technique (mean $5.0 \mathrm{~cm}^{2}$ ) compared with OAT (mean $1.9 \mathrm{~cm}^{2}$ ) and AMIC (mean $3.6 \mathrm{~cm}^{2}$ ). However, with regard to the Kujala score, ACI had superior improvements when compared to the other techniques. As such, determining clear superiority 


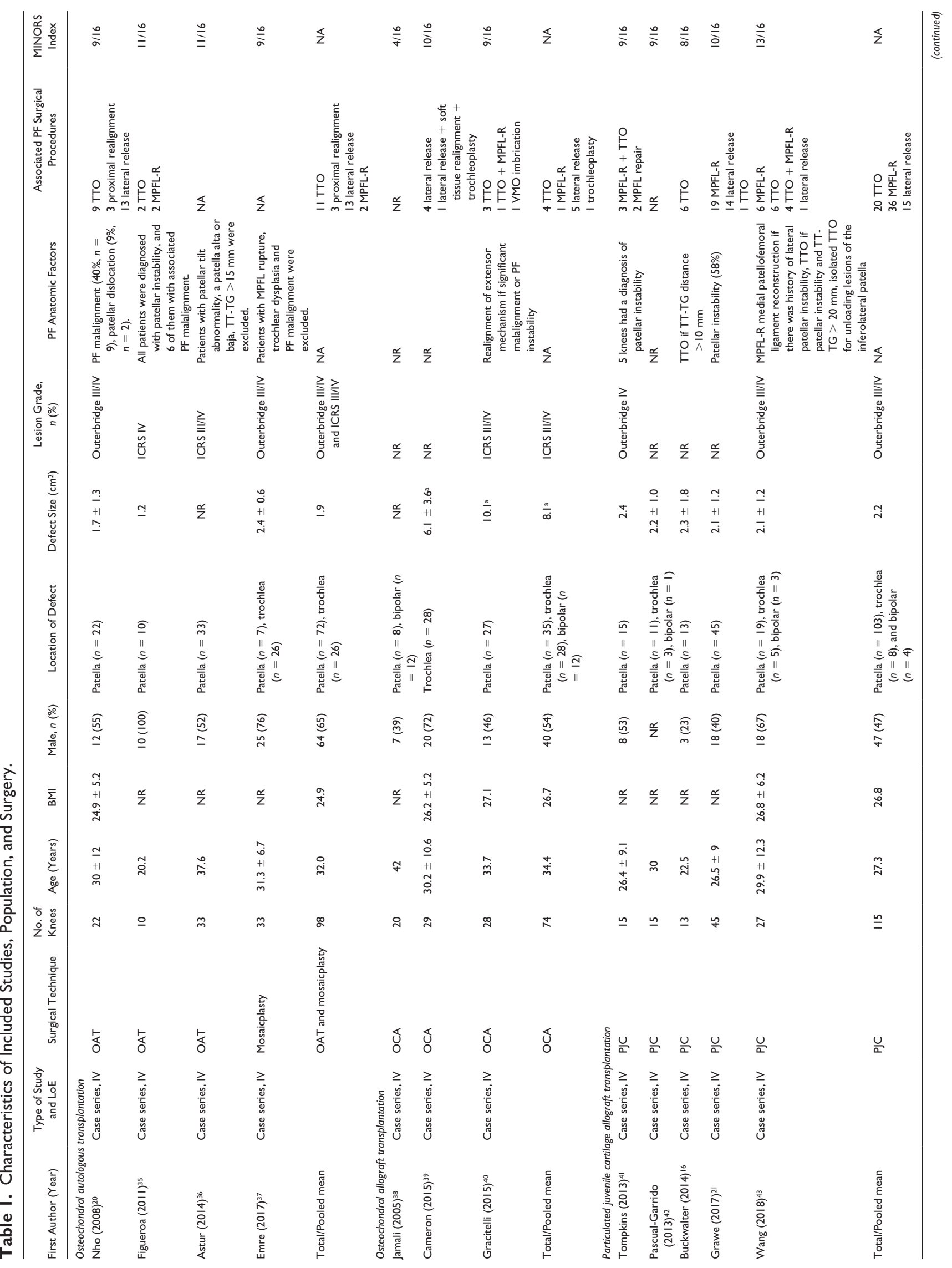




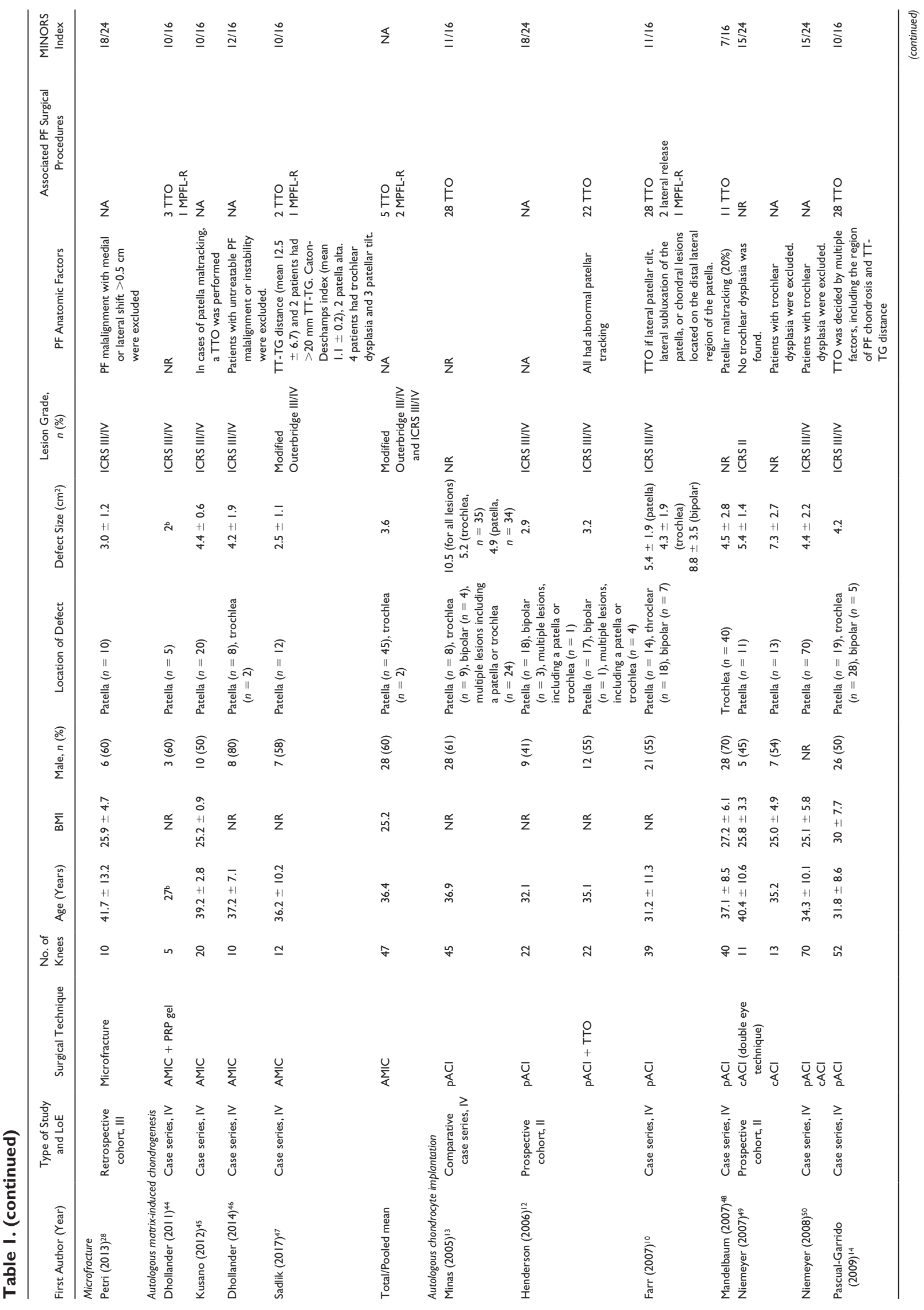




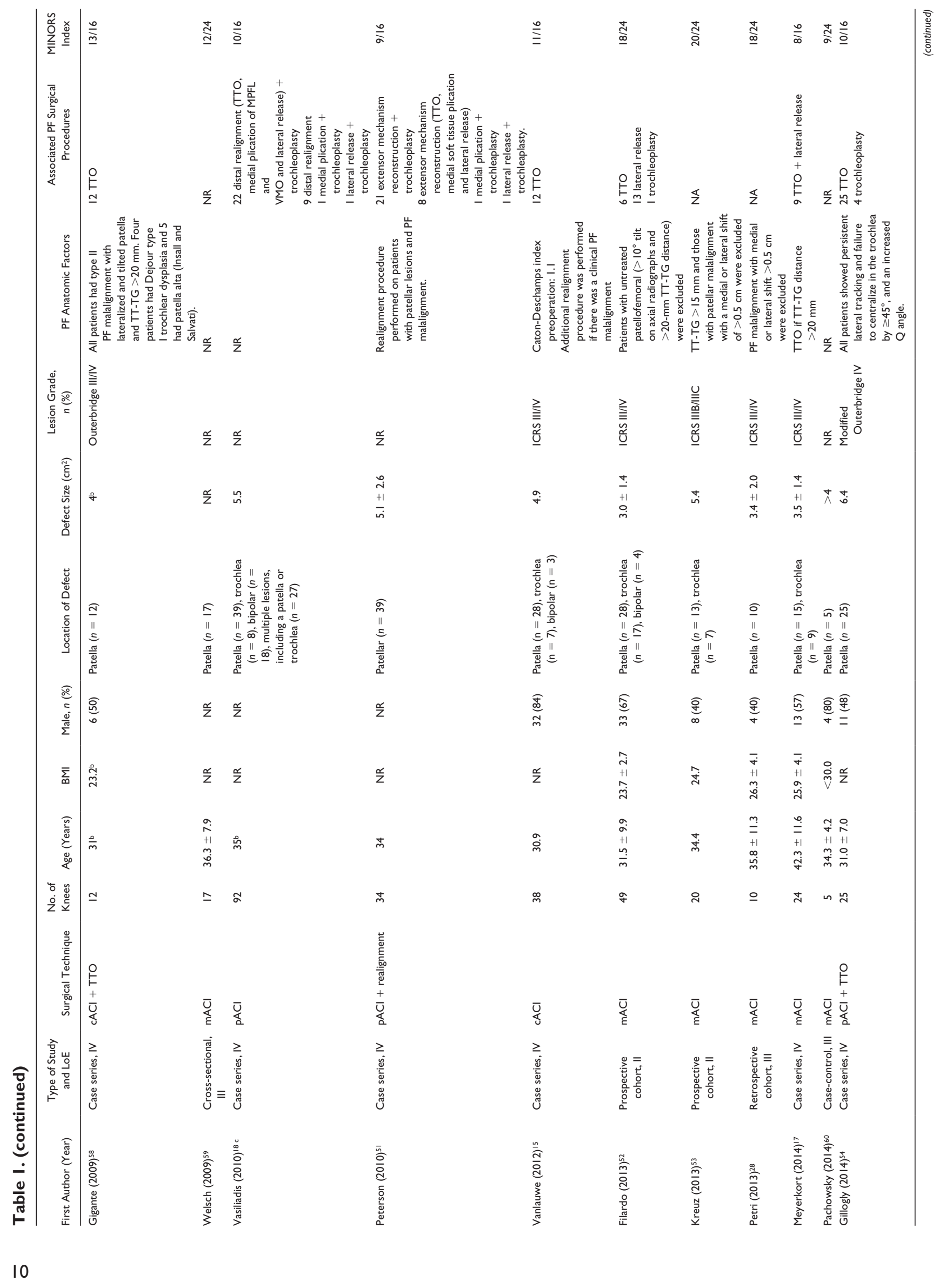




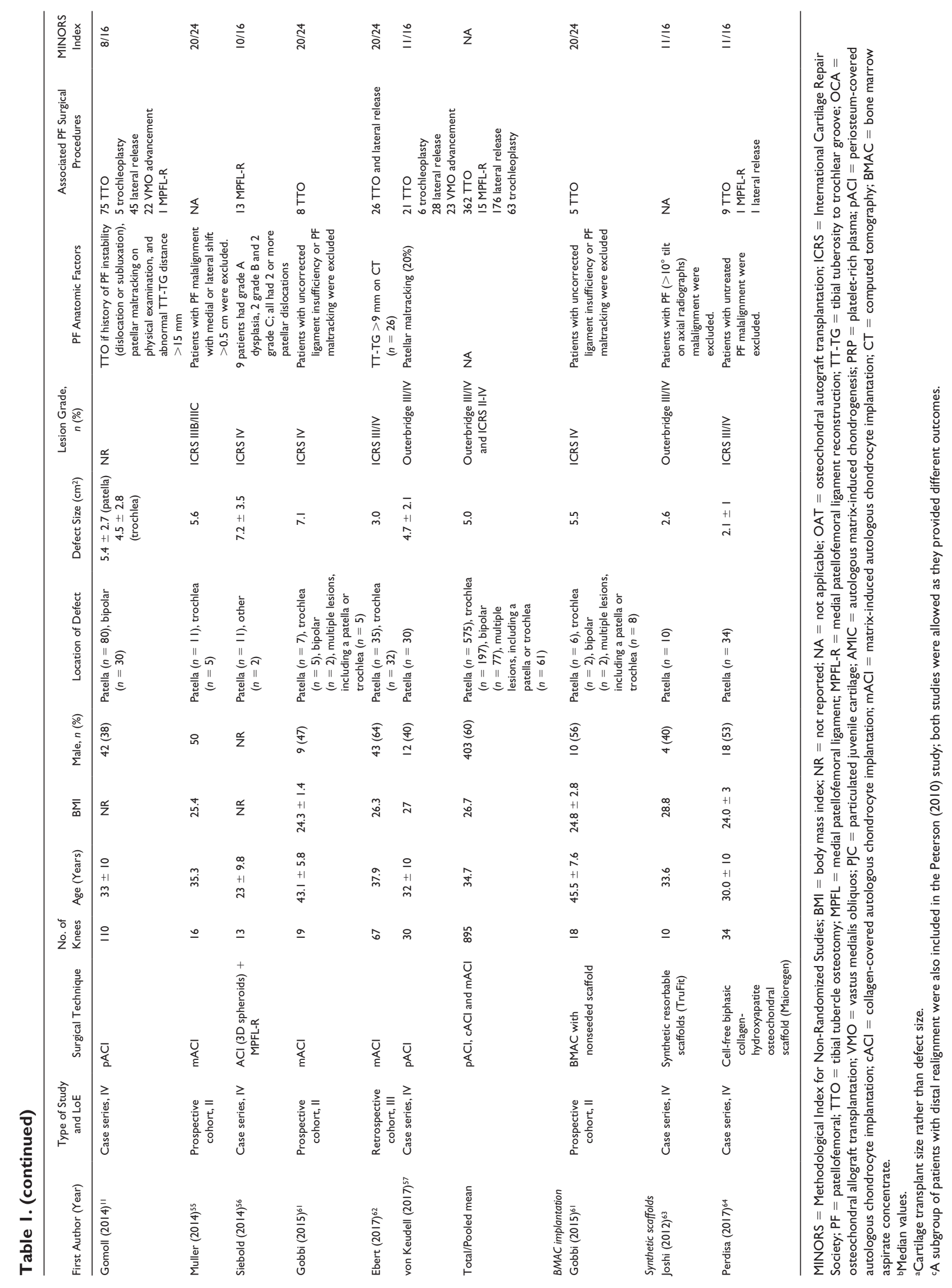




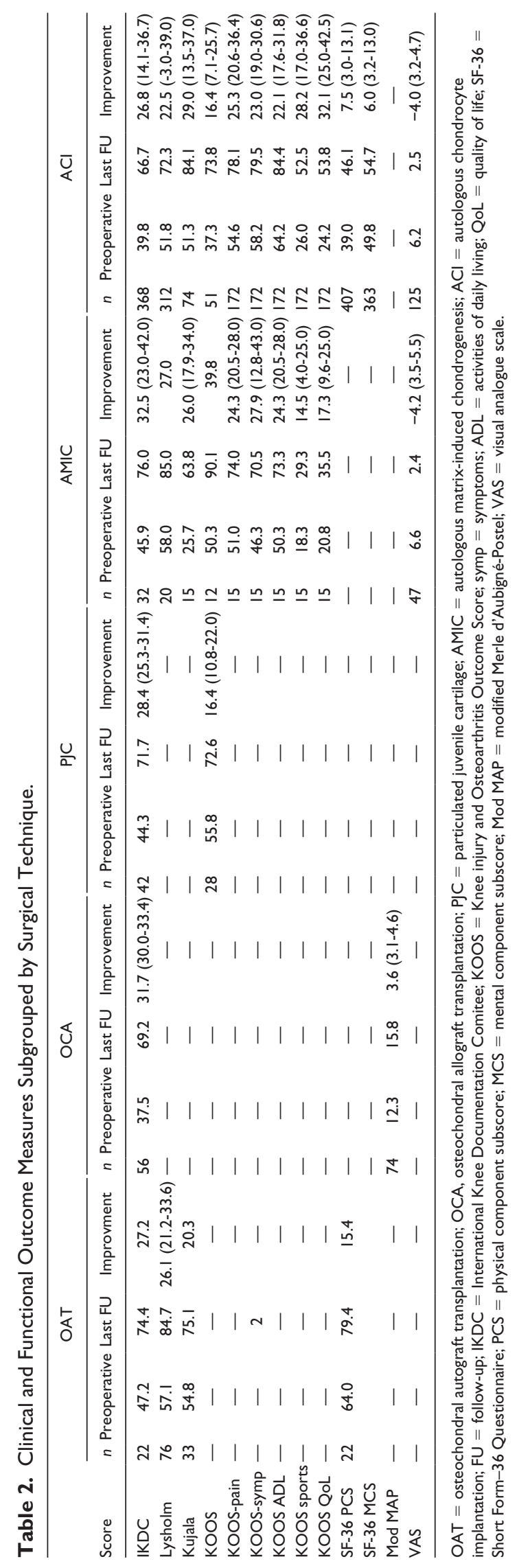


of one technique over the others with regard to the functional outcomes was difficult. Overall, all post-operative outcomes for all surgical techniques surpassed the MCID stipulated for the functional scores in most studies, highlighting that they achieved a substantial clinical improvement. However, the ACI technique showed improvement in Lysholm score that did not achieve the MCID in 2 studies. ${ }^{18,51}$ This finding may be due to a longer follow-up (mean follow-up of 153.6 and 151.2 months, respectively), which may have hampered and even decreased the functional improvement over time. Although infrequently reported, patient postoperative satisfaction was noted to be very high, at $89 \%$ and $84 \%$ for OCA and ACI techniques, respectively.

The MRI follow-up and second-look arthroscopy results provided additional insights on the quality of the repaired tissue. The OAT technique adequately filled the cartilage defects $(>67 \% \text { fill })^{20}$ and provided grafts with hyaline cartilage (ICRS $1 \mathrm{~A}$ in all grafts). ${ }^{35}$ Conflicting evidence was found regarding the surface congruency ${ }^{20,36}$ but grafts were found to have good osseous integration. ${ }^{36}$ The incongruity following OAT likely occurs due to the mismatch between donor and recipient cartilage thickness and contour, which explains the $20 \%$ graft degeneration and ICRS grade II and III scores in the periphery of the plugs. ${ }^{35}$ PJAC usually provided suboptimal cartilage fill (worse than OAT and $\mathrm{ACI}),{ }^{21,42,43}$ but there was one report of at least $90 \%$ fill on $80 \%$ of the patients. ${ }^{41}$ Major disadvantages of PJAC are the considerable risk of graft hypertrophy (range $0 \%$ to $33 \%)^{21,41-43}$ and high rate of synovitis (up to $58 \%$ ) $^{21,42}$ which may be a reaction to the allograft tissue. The AMIC technique showed repair cartilage with poor quality, high rate of incomplete filling ( $40 \%$ to $60 \%$ ), graft hypertrophy ( $20 \%$ to $40 \%$ ) and irregular surface and incomplete integration into the border zone $(20 \%$ to $60 \%) .44,46 \mathrm{ACI}$ technique had the best quality of cartilage among the cell-based techniques, with a high rate of moderate-to-high defect filling $(>50 \%)$ in more than a half of patients, complete integration of the graft in more than half of the patients, $15,17,57,61,62$ with smooth surface $(84 \%$ to $91 \%),{ }^{17,62}$ intact surface without irregularities (58\%), ${ }^{57}$ high incidence of homogenous structure ${ }^{17,62}$ and hypointense or isointense signal. ${ }^{17,57,62}$ In addition, a lower rate of graft hypertrophy was seen as compared with other techniques. $15,17,56,57,61,62$ Second-look arthroscopy confirmed the MRI results, showing a hyaline-like smooth repaired tissue with good filling and integration with the surrounding cartilage. . $^{10,13,53,61}$

The population in this systematic review mostly comprised grade III-IV patellar defects (68\%) and half of the studies included patients with patellofemoral anatomic risk factors. This information is clinically relevant as patellofemoral cartilage injury is often the "tip of the iceberg" and understanding the prevalence patterns of patients with patellofemoral cartilage and associated anatomic abnormalities may be useful to refine current surgical strategies.
Concomitant patellofemoral surgical procedures (TTO, lateral retinacular release, medial patellofemoral ligament reconstruction, or trochleoplasty) are often required to correct extensor mechanism malalignment, patellofemoral maltracking or other related problems (medial patellofemoral ligament rupture or deficiency, excessive lateral reticulum tightness or trochlear dysplasia). A previous systematic review has shown that adding concomitant osteotomy to ACI procedures leads to comparable or even improved results. ${ }^{66}$ Generally, the results of this study showed that performing concomitant patellofemoral associated procedures can achieve results that are comparable to isolated cartilage surgery. ${ }^{10,11,15,17,18,43,45,48,51,57,61,62,64}$ In some cases, associated patellofemoral procedures can enhance the results of cartilage surgery. $12,14,54,56,58$ These findings suggest that associated procedures to correct abnormal anatomy should be performed judiciously and with good reasoning. The appropriate surgical management in these instances remains controversial but should take into account defect location and size, and presence and degree of patellofemoral anatomic risk factors. Treatment algorithms ${ }^{13,14}$ have been developed to help guide the need for associated patellofemoral procedures during cartilage restoration surgery but further studies are necessary to better define surgical guidelines.

The low reporting rates for failures, reoperations and complications in the evaluated studies $(31 \%, 43 \%$, and $43 \%$, respectively) highlights the need for higher compliance of surgical studies in reporting these outcomes and better standardization of the definition of failures and complications related to cartilage restoration procedures. Differing definitions between studies likely leads to variable rates of failures and complications, which may also be in some cases underreported. Thus, for pooling purposes, we used a standardized definition of surgical failures to level the rates of all studies. The overall rate of failures was low $(6 \%$, range $0 \%$ to $29 \%$ ), but OCA demonstrated higher rates of failure than ACI ( $16 \%$ vs $5 \%)$. There was a considerable rate of complications ( $28 \%$, range $0 \%$ to $76 \%$ ) that was comparable across surgical techniques (OAT, 12\%; AMIC, 25\%; ACI, 17.4\%), with the exception of PJAC, which was notably increased (38\%). Finally, the reoperation rates were relatively high $(35 \%$, range $0 \%$ to $67 \%)$, especially for ACI and OCA ( $37 \%$ and $41 \%$, respectively) as compared to PJAC, OAT, and BMAC techniques $(12 \%$, $20 \%$, and $6 \%$, respectively). These are important informations that should be discussed with patients during preoperative counseling. It is worth noting, even though no revisions were needed, that there was a very high plug rate of incorporation failure (replacement of subchondral bone by a cyst) and overlying predominant hyaline articular cartilage lesion (collapse and fissuring $(90 \%)$ and reoperation rate $(70 \%)$ of the synthetic resorbable scaffolds (TruFit), making it a not acceptable option in our opinion. ${ }^{63}$ In contrast, TruFit synthetic implants in the tibiofemoral joint 
have conflicting results. Some studies have shown better clinical, functional and imaging findings at mid to longterm follow-up in the tibio-femoral joint, with a low number of failed cases, ${ }^{67-69}$ while others have reported minimal clinical improvement, ${ }^{70}$ suboptimal MRI results, and a considerable number of failures..$^{71,72}$

Future research should invest into randomized comparative clinical studies comparing two or more different techniques with long-term follow-up to ascertain which would be the best surgical approach for patellofemoral chondral defects. Longer follow-up and reporting of MRI results will provide a more detailed picture of the quality of the repaired grafts and how many are eventually converted to arthroplasty. Subgrouping the analysis by defect location (patella vs. trochlea), location in the patella (medial, lateral, or central), polarity (uni- or bipolar), defect size $(<2$ or $>2 \mathrm{~cm}$ ), containment (contained or noncontained) and association with concomitant procedures will provide important information to refine the current available treatment algorithms with regard to the cartilage restoration itself, as well as the treatment of anatomic abnormalities. Of course, we realize that the variability in presentation and etiology of this disease process makes the above a challenging undertaking. In addition, we encourage the widespread use of the KOOS-PF subscale (11 items) ${ }^{73}$ in conjunction with KOOS score to retrieve additional information regarding symptoms relevant to the patellofemoral joint and to evaluate change over time $(\mathrm{MCID}=+16)$.

This review has some limitations that are inherent to the design of the included studies and to the large spectrum of pathology of patellofemoral cartilage lesions. The lack of comparative studies is one of the major limitations. Importantly, some of the included studies had a low number of included patients (95\% of studies did not even perform power analysis) leading to potential bias (under- or overestimation) and small power. ${ }^{74}$ To reduce the unfavorable effect of a low number of patients, we pooled patients to increase the power of the analysis. Those factors reflect in a mean $60 \%$ and $70 \%$ of the perfect MINORS score. In addition, there is a potentially high risk of bias in the patient selection many of the studies were at a high risk of selection bias (no randomization) and detection bias (lack of or inappropriate blinding). Finally, the high heterogeneity in variables that can be potential confounding factors, such as patient demographic characteristics, lesion characteristics, concomitant pathology and associated surgical procedures and follow-up, precluded a clear comparison of the techniques and a meta-analysis.

\section{Conclusion}

Different surgical approaches (osteochondral autograft transfer, osteochondral allograft transplantation, particulated juvenile cartilage allograft transplantation, and autologous chondrocyte implantation techniques) provided good postoperative outcomes with significant improvements and low rates of failure and should be considered valid options for treating patellofemoral chondral and osteochondral defects. Nevertheless, no definitive conclusion could be made in terms of identifying the best surgical technique, and as such the treatment choice should be based on surgeon preference, and patient and defect characteristics.

\section{Acknowledgments and Funding}

The author(s) received no financial support for the research, authorship, and/or publication of this article.

\section{Declaration of Conflicting Interests}

The author(s) declared no potential conflicts of interest with respect to the research, authorship, and/or publication of this article.

\section{ORCID iD}

João Espregueira-Mendes (iD https://orcid.org/0000-0001-7429 $-4900$

\section{References}

1. Hinckel BB, Gomoll AH. Patellofemoral cartilage restoration: indications, techniques, and outcomes of autologous chondrocytes implantation, matrix-induced chondrocyte implantation, and particulated juvenile allograft cartilage. J Knee Surg. 2018;31:212-26.

2. Chahla J, Sweet MC, Okoroha KR, Nwachukwu BU, Hinckel $\mathrm{B}$, Farr J, et al. Osteochondral allograft transplantation in the patellofemoral joint: a systematic review. Am J Sports Med. 2019;47:3009-18. doi:10.1177/0363546518814236

3. Widuchowski W, Widuchowski J, Trzaska T. Articular cartilage defects: study of 25124 knee arthroscopies. Knee. 2007; 14:177-82.

4. Arøen A, Løken S, Heir S, Alvik E, Ekeland A, Granlund OG, et al. Articular cartilage lesions in 993 consecutive knee arthroscopies. Am J Sports Med. 2004;32:211-5.

5. Hjelle K, Solheim E, Strand T, Muri R, Brittberg M. Articular cartilage defects in 1000 knee arthroscopies. Arthroscopy. 2002;18:730-4.

6. Flanigan DC, Harris JD, Trinh TQ, Siston RA, Brophy RH. Prevalence of chondral defects in athletes' knees: a systematic review. Med Sci Sports Exerc. 2010;42:1795-801.

7. Andrade R, Vasta S, Papalia R, Pereira H, Oliveira JM, Reis $\mathrm{RL}$, et al. Prevalence of articular cartilage lesions and surgical clinical outcomes in football (soccer) players' knees: a systematic review. Arthroscopy. 2016;32:1466-77.

8. Yanke AB, Wuerz T, Saltzman BM, Butty D, Cole BJ. Management of patellofemoral chondral injuries. Clin Sports Med. 2014;33:477-500.

9. Redondo ML, Beer AJ, Yanke AB. Cartilage restoration: microfracture and osteochondral autograft transplantation. J Knee Surg. 2018;31:231-8. 
10. Farr J. Autologous chondrocyte implantation improves patellofemoral cartilage treatment outcomes. Clin Orthop Relat Res. 2007;463:187-94.

11. Gomoll AH, Gillogly SD, Cole BJ, Farr J, Arnold R, Hussey $\mathrm{K}$, et al. Autologous chondrocyte implantation in the patella: a multicenter experience. Am J Sports Med. 2014;42:1074-81.

12. Henderson IJ, Lavigne P. Periosteal autologous chondrocyte implantation for patellar chondral defect in patients with normal and abnormal patellar tracking. Knee. 2006;13:274-9.

13. Minas $T$, Bryant $T$. The role of autologous chondrocyte implantation in the patellofemoral joint. Clin Orthop Relat Res. 2005;(436):30-9.

14. Pascual-Garrido C, Slabaugh MA, L'Heureux DR, Friel NA, Cole BJ. Recommendations and treatment outcomes for patellofemoral articular cartilage defects with autologous chondrocyte implantation: prospective evaluation at average 4-year follow-up. Am J Sports Med. 2009;37(Suppl 1):33S-41S.

15. Vanlauwe JJ, Claes T, Van Assche D, Bellemans J, Luyten FP. Characterized chondrocyte implantation in the patellofemoral joint: an up to 4-year follow-up of a prospective cohort of 38 patients. Am J Sports Med. 2012;40:1799-807.

16. Buckwalter JA, Bowman GN, Albright JP, Wolf BR, Bollier M. Clinical outcomes of patellar chondral lesions treated with juvenile particulated cartilage allografts. Iowa Orthop J. 2014;34:44-9.

17. Meyerkort D, Ebert JR, Ackland TR, Robertson WB, Fallon $\mathrm{M}$, Zheng $\mathrm{MH}$, et al. Matrix-induced autologous chondrocyte implantation (MACI) for chondral defects in the patellofemoral joint. Knee Surg Sports Traumatol Arthrosc. 2014;22:2522-30.

18. Vasiliadis HS, Lindahl A, Georgoulis AD, Peterson L. Malalignment and cartilage lesions in the patellofemoral joint treated with autologous chondrocyte implantation. Knee Surg Sports Traumatol Arthrosc. 2011;19:452-7.

19. Minas T, Von Keudell A, Bryant T, Gomoll AH. The John Insall Award: a minimum 10-year outcome study of autologous chondrocyte implantation. Clin Orthop Relat Res. 2014;472:41-51.

20. Nho SJ, Foo LF, Green DM, Shindle MK, Warren RF, Wickiewicz TL, et al. Magnetic resonance imaging and clinical evaluation of patellar resurfacing with press-fit osteochondral autograft plugs. Am J Sports Med. 2008;36:1101-9.

21. Grawe B, Burge A, Nguyen J, Strickland S, Warren R, Rodeo $\mathrm{S}$, et al. Cartilage regeneration in full-thickness patellar chondral defects treated with particulated juvenile articular allograft cartilage: an MRI analysis. Cartilage. 2017;8:374-83.

22. Sheppard WL, Hinckel BB, Arshi A, Sherman SL, Jones $\mathrm{KJ}$. Accurate reporting of concomitant procedures is highly variable in studies investigating knee cartilage restoration. Cartilage. Epub 2019 Apr 11.

23. Mestriner AB, Ackermann J, Gomoll AH. Patellofemoral cartilage repair. Curr Rev Musculoskelet Med. 2018;11:188-200.

24. Strauss EJ, Galos DK. The evaluation and management of cartilage lesions affecting the patellofemoral joint. Curr Rev Musculoskelet Med. 2013;6:141-9.

25. Brophy RH, Wojahn RD, Lamplot JD. Cartilage restoration techniques for the patellofemoral joint. J Am Acad Orthop Surg. 2017;25:321-9.
26. Mouzopoulos G, Borbon C, Siebold R. Patellar chondral defects: a review of a challenging entity. Knee Surg Sports Traumatol Arthrosc. 2011;19:1990-2001.

27. Noyes FR, Barber-Westin SD. Advanced patellofemoral cartilage lesions in patients younger than 50 years of age: is there an ideal operative option? Arthroscopy. 2013;29:1423-36.

28. Petri M, Broese M, Simon A, Liodakis E, Ettinger M, Guenther D, et al. CaReS (MACT) versus microfracture in treating symptomatic patellofemoral cartilage defects: a retrospective matched-pair analysis. J Orthop Sci. 2013;18:38-44.

29. Moher D, Liberati A, Tetzlaff J, Altman DG; PRISMA Group. Preferred reporting items for systematic reviews and meta-analyses: the PRISMA statement. Ann Intern Med. 2009;151:264-9.

30. Irrgang J, Anderson A, Dunn W, et al. Summary of clinical outcome measures for sports-related knee injuries. https:// www.sportsmed.org/AOSSMIMIS/members/downloads/ research/ClinicalOutcomeMeasuresKnee.pdf. Published June 5, 2012. Accessed November 22, 2019.

31. Roos EM, Lohmander LS. The Knee injury and Osteoarthritis Outcome Score (KOOS): from joint injury to osteoarthritis. Health Qual Life Outcomes. 2003;1:64.

32. Bennell K, Bartam S, Crossley K, Green S. Outcome measures in patellofemoral pain syndrome: test retest reliability and inter-relationships. Phys Ther Sport. 2000;1:32-41.

33. Crossley KM, Bennell KL, Cowan SM, Green S. Analysis of outcome measures for persons with patellofemoral pain: which are reliable and valid? Arch Phys Med Rehabil. 2004;85:815-22.

34. Slim K, Nini E, Forestier D, Kwiatkowski F, Panis Y, Chipponi J. Methodological Index for Non-Randomized Studies (MINORS): development and validation of a new instrument. ANZ J Surg. 2003;73:712-6.

35. Figueroa D, Melean P, Calvo R, Gili F, Zilleruelo N, Vaisman A. Osteochondral autografts in full thickness patella cartilage lesions. Knee. 2011;18:220-3.

36. Astur DC, Arliani GG, Binz M, Astur N, Kaleka CC, Amaro JT, et al. Autologous osteochondral transplantation for treating patellar chondral injuries: evaluation, treatment, and outcomes of a two-year follow-up study. J Bone Joint Surg Am. 2014;96:816-23.

37. Emre TY, Atbasi Z, Demircioglu DT, Uzun M, Kose O. Autologous osteochondral transplantation (mosaicplasty) in articular cartilage defects of the patellofemoral joint: retrospective analysis of 33 cases. Musculoskelet Surg. 2017;101:133-8.

38. Jamali AA, Emmerson BC, Chung C, Convery FR, Bugbee WD. Fresh osteochondral allografts: results in the patellofemoral joint. Clin Orthop Relat Res. 2005;(437):176-85.

39. Cameron JI, Pulido PA, McCauley JC, Bugbee WD. Osteochondral allograft transplantation of the femoral trochlea. Am J Sports Med. 2016;44:633-8.

40. Gracitelli GC, Meric G, Pulido PA, Görtz S, De Young AJ, Bugbee WD. Fresh osteochondral allograft transplantation for isolated patellar cartilage injury. Am J Sports Med. 2015;43:879-84.

41. Tompkins M, Hamann JC, Diduch DR, Bonner KF, Hart JM, Gwathmey FW, et al. Preliminary results of a novel singlestage cartilage restoration technique: particulated juvenile 
articular cartilage allograft for chondral defects of the patella. Arthroscopy. 2013;29:1661-70.

42. Pascual-Garrido C, Gold SL, Snikeris J, Burge A, Nguyen $\mathrm{J}$, Potter HG, et al. Magnetic resonance imaging and clinical evaluation of chondral lesions treated with allografts juvenile cells. Orthop J Sports Med. 2013;1(4 Suppl):23259671 13S2325900030.

43. Wang T, Belkin NS, Burge AJ, Chang B, Pais M, Mahony $\mathrm{G}$, et al. Patellofemoral cartilage lesions treated with particulated juvenile allograft cartilage: a prospective study with minimum 2-year clinical and magnetic resonance imaging outcomes. Arthroscopy. 2018;34:1498-505.

44. Dhollander AA, De Neve F, Almqvist KF, Verdonk R, Lambrecht S, Elewaut D, et al. Autologous matrix-induced chondrogenesis combined with platelet-rich plasma gel: technical description and a five pilot patients report. Knee Surg Sports Traumatol Arthrosc. 2011;19:536-42.

45. Kusano T, Jakob RP, Gautier E, Magnussen RA, Hoogewoud $\mathrm{H}$, Jacobi M. Treatment of isolated chondral and osteochondral defects in the knee by autologous matrix-induced chondrogenesis (AMIC). Knee Surg Sports Traumatol Arthrosc. 2012;20:2109-15.

46. Dhollander A, Moens K, Van der Maas J, Verdonk P, Almqvist KF, Victor J. Treatment of patellofemoral cartilage defects in the knee by autologous matrix-induced chondrogenesis (AMIC). Acta Orthop Belg. 2014;80:251-9.

47. Sadlik B, Puszkarz M, Kosmalska L, Wiewiorski M. Allarthroscopic autologous matrix-induced chondrogenesisaided repair of a patellar cartilage defect using dry arthroscopy and a retraction system. J Knee Surg. 2017;30:925-9.

48. Mandelbaum B, Browne JE, Fu F, Micheli LJ, Moseley JB Jr, Erggelet $\mathrm{C}$, et al. Treatment outcomes of autologous chondrocyte implantation for full-thickness articular cartilage defects of the trochlea. Am J Sports Med. 2007;35:915-21.

49. Niemeyer P, Kreuz PC, Steinwachs M, Köstler W, Mehlhorn A, Kraft N, et al. Technical note: the "double eye" technique as a modification of autologous chondrocyte implantation for the treatment of retropatellar cartilage defects. Knee Surg Sports Traumatol Arthrosc. 2007;15:1461-8.

50. Niemeyer P, Steinwachs M, Erggelet C, Kreuz PC, Kraft N, Köstler W, et al. Autologous chondrocyte implantation for the treatment of retropatellar cartilage defects: clinical results referred to defect localisation. Arch Orthop Trauma Surg. 2008;128:1223-31.

51. Peterson L, Vasiliadis HS, Brittberg M, Lindahl A. Autologous chondrocyte implantation: a long-term follow-up. Am J Sports Med. 2010;38:1117-24.

52. Filardo G, Kon E, Andriolo L, Di Martino A, Zaffagnini S, Marcacci M. Treatment of "patellofemoral" cartilage lesions with matrix-assisted autologous chondrocyte transplantation: a comparison of patellar and trochlear lesions. Am J Sports Med. 2014;42:626-34.

53. Kreuz PC, Müller S, von Keudell A, Tischer T, Kaps C, Niemeyer $\mathrm{P}$, et al. Influence of sex on the outcome of autologous chondrocyte implantation in chondral defects of the knee. Am J Sports Med. 2013;41:1541-8.

54. Gillogly SD, Arnold RM. Autologous chondrocyte implantation and anteromedialization for isolated patellar articular cartilage lesions: 5- to 11-year follow-up. Am J Sports Med. 2014;42:912-20.

55. Muller S, Hirschmuller A, Erggelet C, Beckmann NA, Kreuz PC. Significantly worse isokinetic hamstring-quadriceps ratio in patellofemoral compared to condylar defects 4 years after autologous chondrocyte implantation. Knee Surg Sports Traumatol Arthrosc. 2015;23:2151-8.

56. Siebold R, Karidakis G, Fernandez F. Clinical outcome after medial patellofemoral ligament reconstruction and autologous chondrocyte implantation following recurrent patella dislocation. Knee Surg Sports Traumatol Arthrosc. 2014;22:2477-83.

57. von Keudell A, Han R, Bryant T, Minas T. Autologous chondrocyte implantation to isolated patella cartilage defects: twoto 15-year follow-up. Cartilage. 2017;8:146-54.

58. Gigante A, Enea D, Greco F, Bait C, Denti M, Schonhuber H, et al. Distal realignment and patellar autologous chondrocyte implantation: mid-term results in a selected population. Knee Surg Sports Traumatol Arthrosc. 2009;17:2-10.

59. Welsch GH, Mamisch TC, Quirbach S, Zak L, Marlovits $\mathrm{S}$, Trattnig S. Evaluation and comparison of cartilage repair tissue of the patella and medial femoral condyle by using morphological MRI and biochemical zonal T2 mapping. Eur Radiol. 2009;19:1253-62.

60. Pachowsky ML, Trattnig S, Wondrasch B, Apprich S, Marlovits S, Mauerer A, et al. In vivo evaluation of biomechanical properties in the patellofemoral joint after matrixassociated autologous chondrocyte transplantation by means of quantitative T2 MRI. Knee Surg Sports Traumatol Arthrosc. 2014;22:1360-9.

61. Gobbi A, Chaurasia S, Karnatzikos G, Nakamura N. Matrix-induced autologous chondrocyte implantation versus multipotent stem cells for the treatment of large patellofemoral chondral lesions: a nonrandomized prospective trial. Cartilage. 2015;6:82-97.

62. Ebert JR, Schneider A, Fallon M, Wood DJ, Janes GC. A comparison of 2-year outcomes in patients undergoing tibiofemoral or patellofemoral matrix-induced autologous chondrocyte implantation. Am J Sports Med. 2017;45:3243-53.

63. Joshi N, Reverte-Vinaixa M, Diaz-Ferreiro EW, DominguezOronoz R. Synthetic resorbable scaffolds for the treatment of isolated patellofemoral cartilage defects in young patients: magnetic resonance imaging and clinical evaluation. Am J Sports Med. 2012;40:1289-95.

64. Perdisa F, Filardo G, Sessa A, Busacca M, Zaffagnini S, Marcacci $\mathrm{M}$, et al. One-step treatment for patellar cartilage defects with a cell-free osteochondral scaffold: a prospective clinical and MRI evaluation. Am J Sports Med. 2017;45:1581-8.

65. Shanmugaraj A, Coughlin RP, Kuper GN, Ekhtiari S, Simunovic N, Musahl V, et al. Changing trends in the use of cartilage restoration techniques for the patellofemoral joint: a systematic review. Knee Surg Sports Traumatol Arthrosc. 2019;27:854-67.

66. Trinh TQ, Harris JD, Siston RA, Flanigan DC. Improved outcomes with combined autologous chondrocyte implantation and patellofemoral osteotomy versus isolated autologous chondrocyte implantation. Arthroscopy. 2013;29:566-74. 
67. Bugelli G, Ascione F, Dell'Osso G, Zampa V, Giannotti S. Biphasic bioresorbable scaffold (TruFit ${ }^{\circledR}$ ) in knee osteochondral defects: 3-T MRI evaluation of osteointegration in patients with a 5-year minimum follow-up. Musculoskelet Surg. 2018;102:191-9.

68. Dell'Osso G, Bottai V, Bugelli G, Manisco T, Cazzella N, Celli $\mathrm{F}$, et al. The biphasic bioresorbable scaffold (Trufit ${ }^{\circledR}$ ) in the osteochondral knee lesions: long-term clinical and MRI assessment in 30 patients. Musculoskelet Surg. 2016;100:93-6.

69. Bekkers JE, Bartels LW, Vincken KL, Dhert WJ, Creemers LB, Saris DB. Articular cartilage evaluation after TruFit plug implantation analyzed by delayed gadolinium-enhanced MRI of cartilage (dGEMRIC). Am J Sports Med. 2013;41: 1290-5.

70. Azam A, Forster M, Robertson A. Clinical and radiological outcome for Trufit plug in the treatment of chondral and osteochondral lesions at a minimum of 2 years. J Orthop. 2018; $15: 47-51$

71. Gelber PE, Batista J, Millan-Billi A, Patthauer L, Vera S, Gomez-Masdeu M, et al. Magnetic resonance evaluation of TruFit(®) plugs for the treatment of osteochondral lesions of the knee shows the poor characteristics of the repair tissue. Knee. 2014;21:827-32.

72. Barber FA, Dockery WD. A computed tomography scan assessment of synthetic multiphase polymer scaffolds used for osteochondral defect repair. Arthroscopy. 2011;27:60-4.

73. Crossley KM, Macri EM, Cowan SM, Collins NJ, Roos EM. The patellofemoral pain and osteoarthritis subscale of the KOOS (KOOS-PF): development and validation using the COSMIN checklist. Br J Sports Med. 2018;52:1130-6.

74. Ioannidis JPA. Why most published research findings are false. PLoS Med. 2005;2:e124. 